\title{
Assessment of High Gamma Prime Ni- base Superalloy Processability, Geometric Accuracy, and Component Fabricability
}

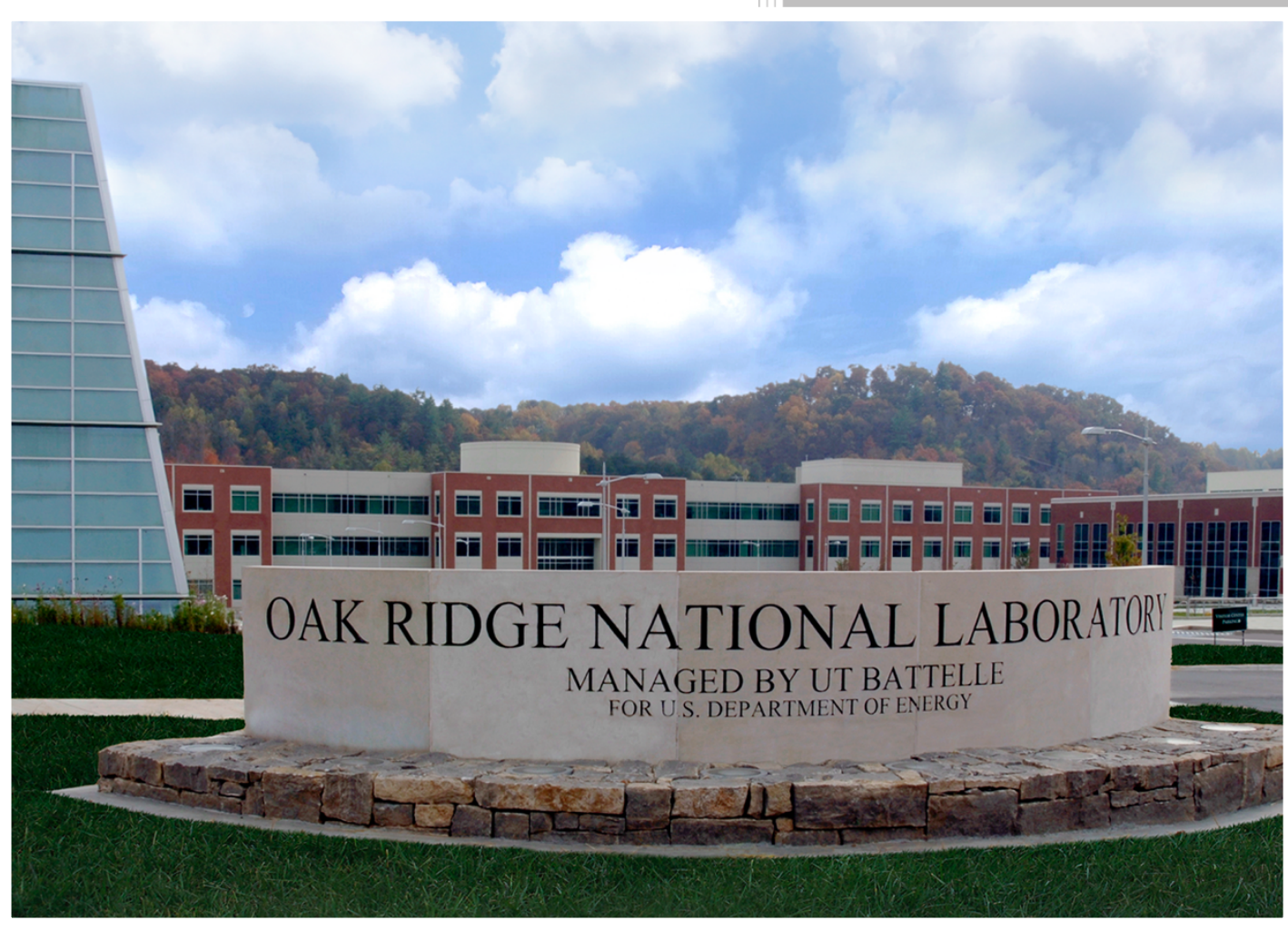

Michael M. Kirka

November $10^{\text {th }}, 2019$

CRADA FINAL REPORT

NFE-17-06955

Approved for Public Release. Distribution is Unlimited. 


\title{
DOCUMENT AVAILABILITY
}

Reports produced after January 1, 1996, are generally available free via US Department of Energy (DOE) SciTech Connect.

Website http://www.osti.gov/scitech/

Reports produced before January 1, 1996, may be purchased by members of the public from the following source:

\author{
National Technical Information Service \\ 5285 Port Royal Road \\ Springfield, VA 22161 \\ Telephone 703-605-6000 (1-800-553-6847) \\ TDD 703-487-4639 \\ Fax 703-605-6900 \\ E-mail info@ntis.gov \\ Website http://www.ntis.gov/help/ordermethods.aspx
}

Reports are available to DOE employees, DOE contractors, Energy Technology Data Exchange representatives, and International Nuclear Information System representatives from the following source:

Office of Scientific and Technical Information

PO Box 62

Oak Ridge, TN 37831

Telephone 865-576-8401

Fax 865-576-5728

E-mail reports@osti.gov

Website http://www.osti.gov/contact.html

This report was prepared as an account of work sponsored by an agency of the United States Government. Neither the United States Government nor any agency thereof, nor any of their employees, makes any warranty, express or implied, or assumes any legal liability or responsibility for the accuracy, completeness, or usefulness of any information, apparatus, product, or process disclosed, or represents that its use would not infringe privately owned rights. Reference herein to any specific commercial product, process, or service by trade name, trademark, manufacturer, or otherwise, does not necessarily constitute or imply its endorsement, recommendation, or favoring by the United States Government or any agency thereof. The views and opinions of authors expressed herein do not necessarily state or reflect those of the United States Government or any agency thereof. 
Materials Science and Technology Division Advanced Manufacturing Office

\title{
Assessment of High-gamma Prime Ni-base Superalloy Processability, Geometric
} Accuracy, and Component Fabricability

\author{
Authors \\ Michael M. Kirka \\ Yousub Lee \\ Daniel Ryan (Solar Turbines) \\ David Adair (Solar Turbines)
}

Date Published:

November $11^{\text {th }}, 2019$

\author{
Prepared by \\ OAK RIDGE NATIONAL LABORATORY \\ Oak Ridge, Tennessee 37831-6283 \\ managed by \\ UT-BATTELLE, LLC \\ for the \\ US DEPARTMENT OF ENERGY \\ under contract DE-AC05-00OR22725
}


Approved For Public Release 



\section{CONTENTS}

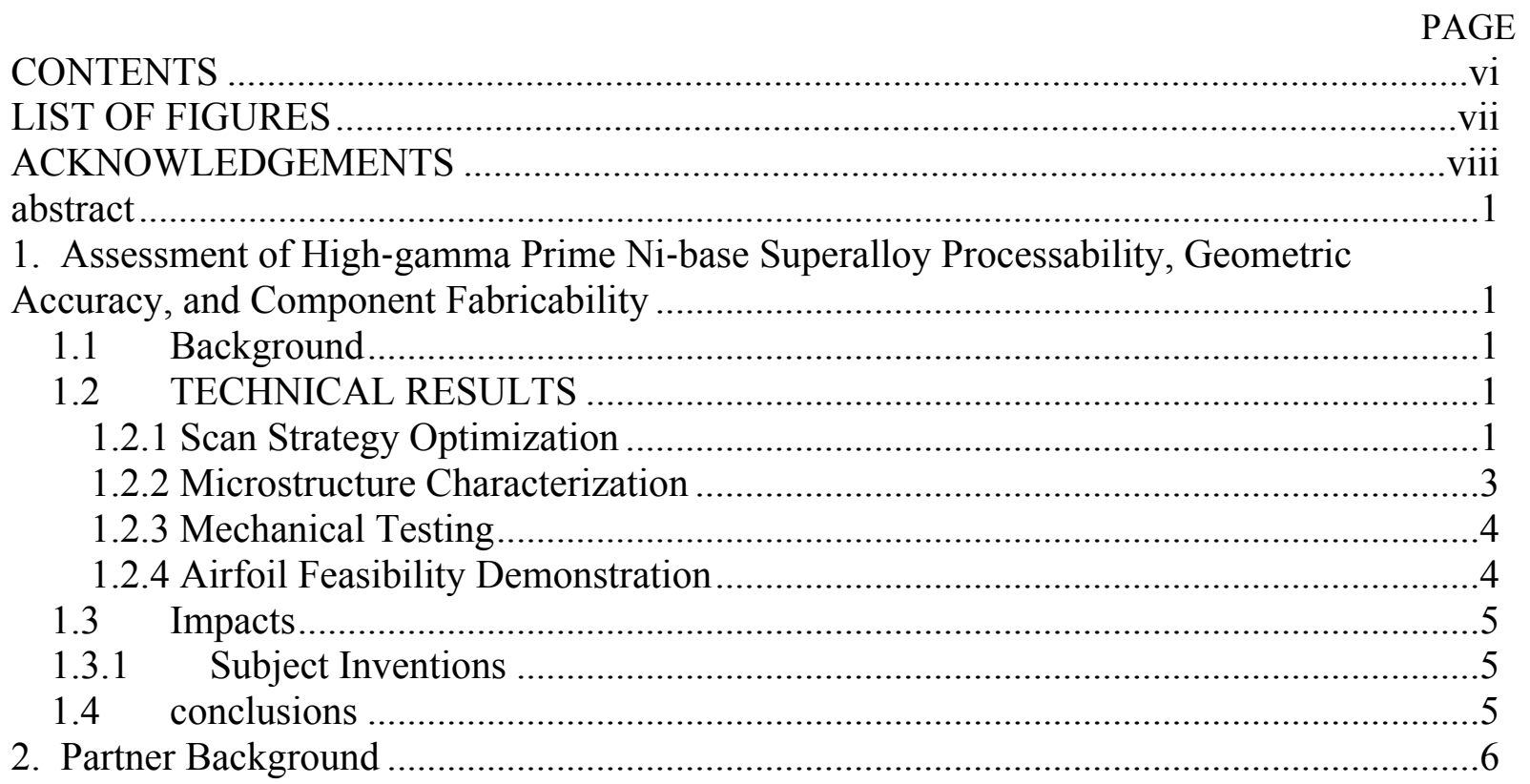




\section{LIST OF FIGURES}

Figure 1: Variation of cracking location and curvature at different height of the airfoil

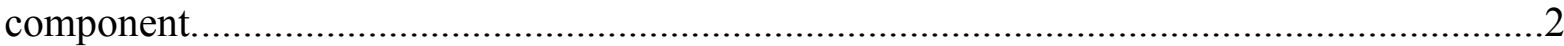

Figure 2: Inhomogeneous temperature distribution at each part. The discrepancy is attributed to the interaction between line length and varying melting length.

Figure 3: As fabricated Gamma prime structure within the airfoil a) At the base of the airfoil

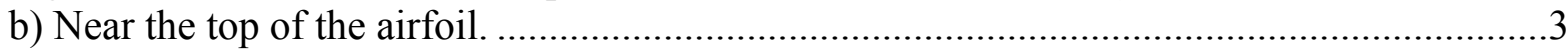

Figure 4: Hot isostatically pressed and heat-treat EBM Inconel 738 microstructure showing the ideal bi-modal gamma prime distribution.............................................................

Figure 5: Textures formed within the modified airfoil geometry as a result of the optimized

process parameters to yield crack free material............................................................4

Figure 6: Tensile Properties of EBM AM Inconel ${ }^{\mathrm{TM}} 738$ samples that were machined from bars and walls after HIP, Solution, and Age heat treatment processing .................................4

Figure 7: Low Cycle Fatigue (LCF) properties of EBM AM Inconel ${ }^{\mathrm{TM}} 738$ samples that were

machined from bars and walls after HIP, Solution, and Age heat treatment processing ..........5 Figure 8: Creep Rupture Larson Miller Parameter (LMP) properties of EBM AM Inconel ${ }^{\mathrm{TM}}$ 738 samples that were machined from vertical bars after HIP, Solution, and Age heat

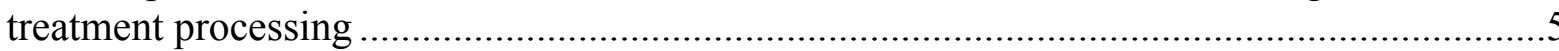

Figure 9: EBM Inconel 738 airfoil fabricated defect-free after geometry and process optimization. 


\section{ACKNOWLEDGEMENTS}

This CRADA NFE-17-06955 was conducted as a Technical Collaboration project within the Oak Ridge National Laboratory (ORNL) Manufacturing Demonstration Facility (MDF) sponsored by the US Department of Energy Advanced Manufacturing Office (CPS Agreement Number 24761).

Opportunities for MDF technical collaborations are listed in the announcement "Manufacturing Demonstration Facility Technology Collaborations for US Manufacturers in Advanced

Manufacturing and Materials Technologies" posted at http:/web.ornl.gov/sci/manufacturing/docs/FBO-ORNL-MDF-2013-2.pdf. The goal of technical collaborations is to engage industry partners to participate in short-term, collaborative projects within the Manufacturing Demonstration Facility (MDF) to assess applicability and of new energy efficient manufacturing technologies. Research sponsored by the U.S. Department of Energy, Office of Energy Efficiency and Renewable Energy, Advanced Manufacturing Office, under contract DE-AC0500OR22725 with UT-Battelle, LLC. 


\begin{abstract}
Additive manufacturing (AM), also known as 3D printing, is a rapidly developing technology with tremendous potential in both developmental and production applications. Solar Turbines Incorporated is committed to AM technology for gas turbine applications. The ability to metal 3D print novel designs of turbine blades capable of actual turbine engine operation would effectively reduce design validation cycle time and allow acquisition of key performance data early in a design campaign. In support of Solar's advanced manufacturing development and ongoing engine efficiency improvement goals, Solar initiated a project to print a full set of Mercury ${ }^{\mathrm{TM}} 50$ stage 2 turbine blades to be run in a development engine, with this Phase 1 program to demonstrate feasibility for fabrication of the geometry from the non-weldable Ni-base superalloy through electron beam melting (EBM).
\end{abstract}

\title{
1. ASSESSMENT OF HIGH-GAMMA PRIME NI-BASE SUPERALLOY PROCESSABILITY, GEOMETRIC ACCURACY, AND COMPONENT FABRICABILITY
}

This phase 1 technical collaboration project (MDF-TC-2017-133) was begun in October, 2017 and was completed on October 10, 2019. The collaboration partner Solar Turbines Incorporated (Solar Turbines) is a large business. Through the development efforts of this program, ORNL and Solar Turbines were able to demonstrate the feasibility for the fabrication of the traditionally non-weldable Ni-base superalloy Inconel 738 through the electron beam melting (EBM) additive manufacturing process.

\subsection{BACKGROUND}

The goal of this project is to determine the suitability and processability of the crack prone high-gamma prime Ni-base superalloy Inconel 738 when processed via additive manufacturing (AM) for fabricating prototype industrial gas turbine hot section components. The ability to rapidly fabricate prototype turbine components from Inconel 738 would allow for significant reductions in the design and validation product development cycle time enabling turbine efficiency improvements. However, for AM processed Inconel 738 to be used to fabricate prototyping hot section components for engine testing, minimum viable mechanical properties must be demonstrated in addition to the capability to produce suitable component geometries. For the purposes of comparing and benchmarking the material performance of EBM Inconel 738, traditionally cast Inconel 738 material is used.

\subsection{TECHNICAL RESULTS}

For this program, gas atomized Inconel 738 obtained from PraxAir was processed in an Arcam Q10+ EBM machine equipped with in-situ near-IR cameras. To aid in the process development, the beam scan strategy was optimized to mitigate cracking in the deposited Inconel 738 material through the aid of computational modeling and in-situ process monitoring. Through optimizing the EBM process, material suitable for mechanical testing was obtained, as well as the demonstration of feasibility for fabricating defect complex airfoil geometries.

\subsubsection{Scan Strategy Optimization}

In-situ near infrared (NIR) images taken from the Inconel 738 builds in the Q10+ machine were used to identify crack locations in the components without the need for destructive evaluation. Throughout the builds, the cracks change direction and location with height. However, the crack locations are consistent in location with regards to build repeatability and change in direction of the beam scan 
(Figure 1(a)-(d)). Interestingly, the crack curvature becomes reversed from concave to convex. Later, the cracking translates to lower region in Figure 1(d). It indicates that the cracking location interacts with part geometry and scan direction.
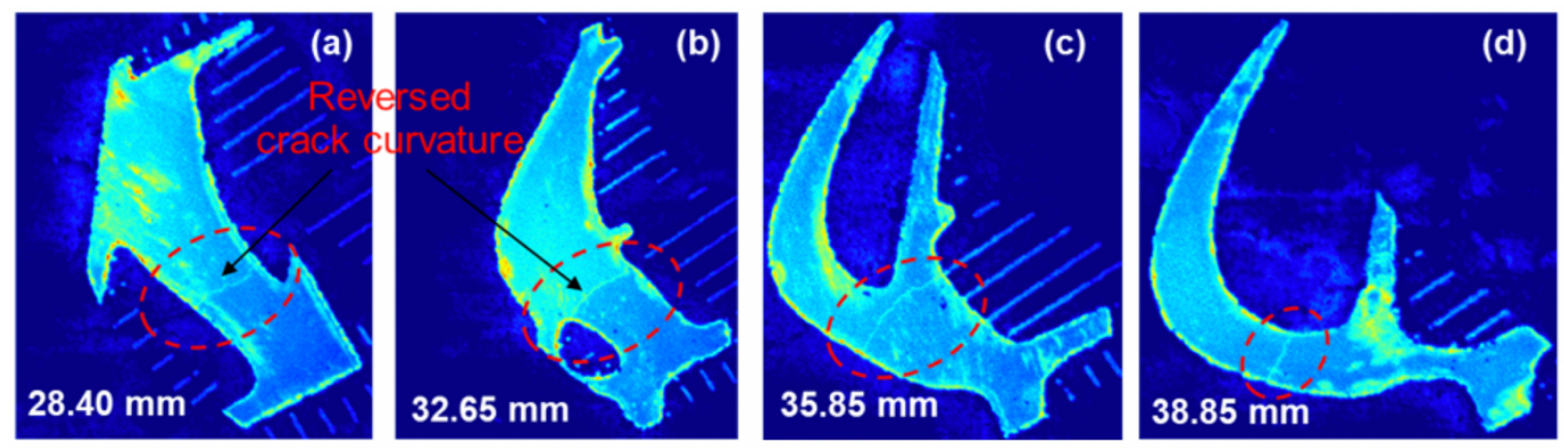

Figure 1: Variation of cracking location and curvature at different height of the airfoil component.

A thermal simulation was performed to confirm the effect of scan direction on temperature distribution. The scan parameters for rater scan were directly converted from the EBM machine for finite element method (FEM) simulation. The beam linearly melts the parts and rotates about $67^{\circ}$ for next layer. The temperature is higher at the right two builds in Figure 2(a) and at the lower two parts in Figure. 2(b). The discrepancy in temperature is attributed to interaction between a fixed line length and varying melting length caused by beam rotation and part geometry.

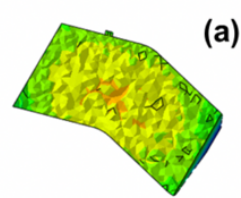

(a)
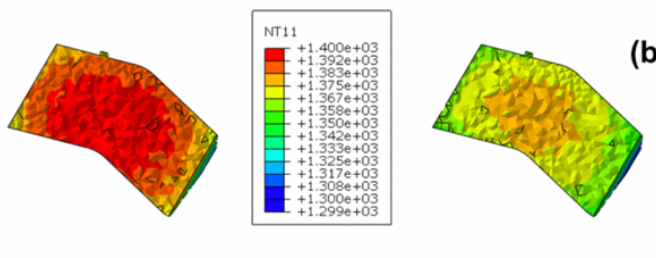

(b)
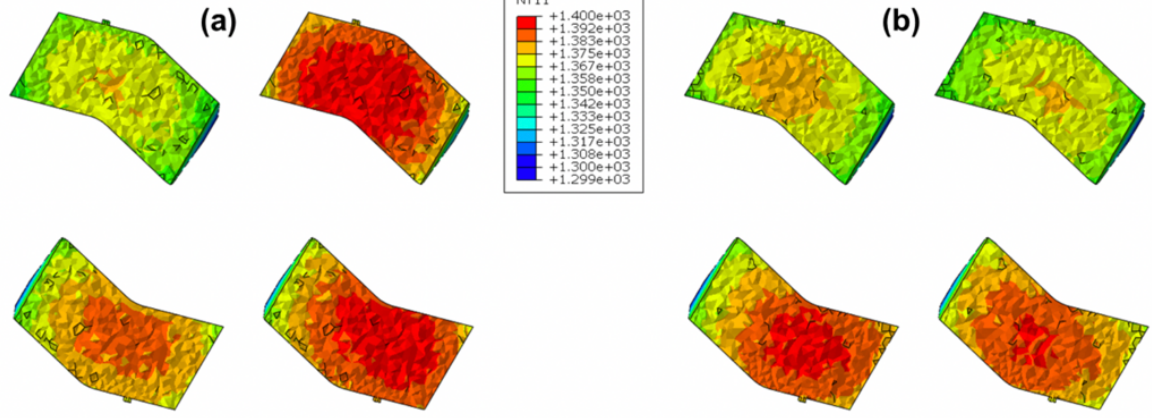

Figure 2: Inhomogeneous temperature distribution at each part. The discrepancy is attributed to the interaction between line length and varying melting length.

To develop an optimized process parameter set, an iterative approach was taken based on in-situ nearIR observations coupled with computational modeling to develop trends in the beam path to unfavorable stress states (i.e. in-plane tensile stresses that lead to cracking). To optimize the process parameters, the rotation of the beam scan pattern, the beam current, and beam scan speed were adjusted. The finer details of the process optimization are not discussed in detail here due to being protected information with the manufacture of the EBM machines.

\subsubsection{Microstructure Characterization}


In the as-built state, the gamma prime precipitate size and volume fraction exhibits a spatial variation within the airfoil that is a function of build height due to the variation in time at temperature of the layers. Representative micrographs from the fir tree (Figure 3a) which was held at temperature the longest indicate an overaged state for the $\gamma$ ' and the shroud (Figure 3b) which spent the shortest time at temperature an underaged $\gamma^{\prime}$ structure. As a result, the material is given a subsequent solution and aging treatment to homogenize the microstructure and optimize the mechanical performance of the material. The properly aged material is shown in Figure 4, which exhibits a bimodal distribution of $\gamma^{\prime}$.

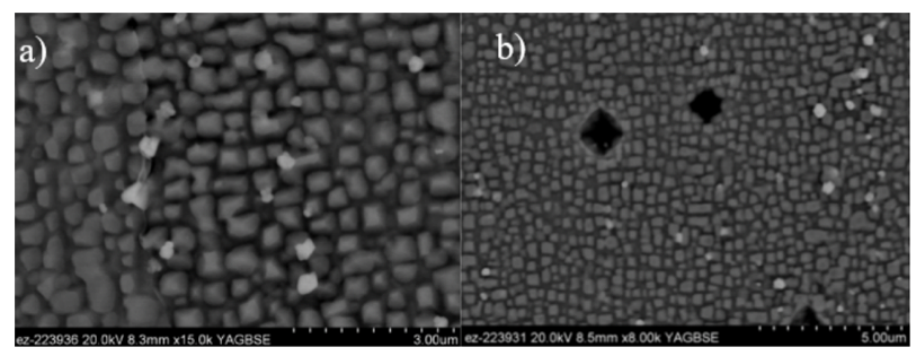

Figure 3: As fabricated Gamma prime structure within the airfoil a) At the base of the airfoil b) Near the top of the airfoil.

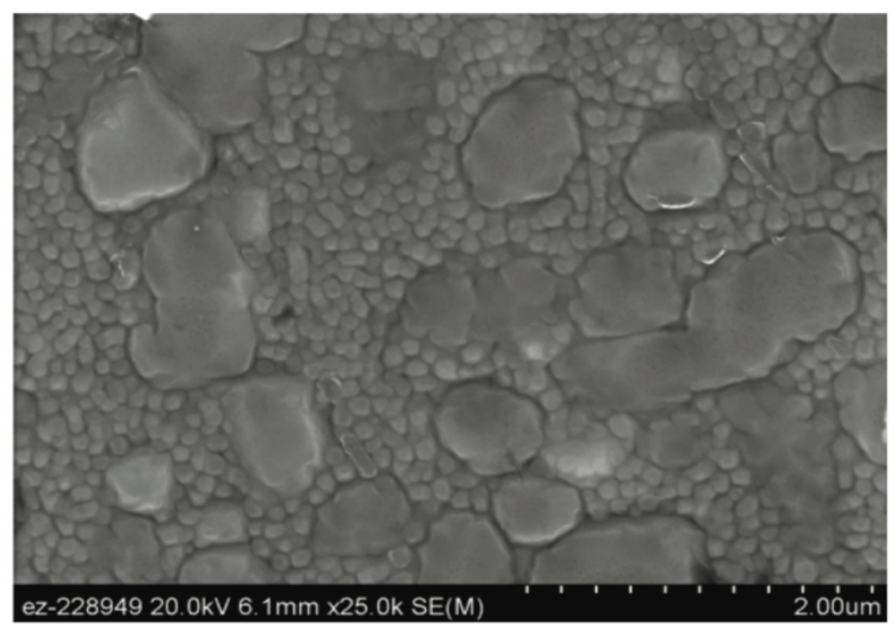

Figure 4: Hot isostatically pressed and heat-treat EBM Inconel 738 microstructure showing the ideal bimodal gamma prime distribution.

In complex geometries such as the airfoil, texture formation is sensitive to local geometry features, and is not by default the typical elongated columnar grain structure aligned with the build direction. Illustrated in Figure 5 are representative EBSD micrographs showing elongated grains aligned with the build direction surrounded by stray elongated grains nucleating from the powder bed in the pressure section of the airfoil and an equiaxed structure in the base of the airfoil section. 


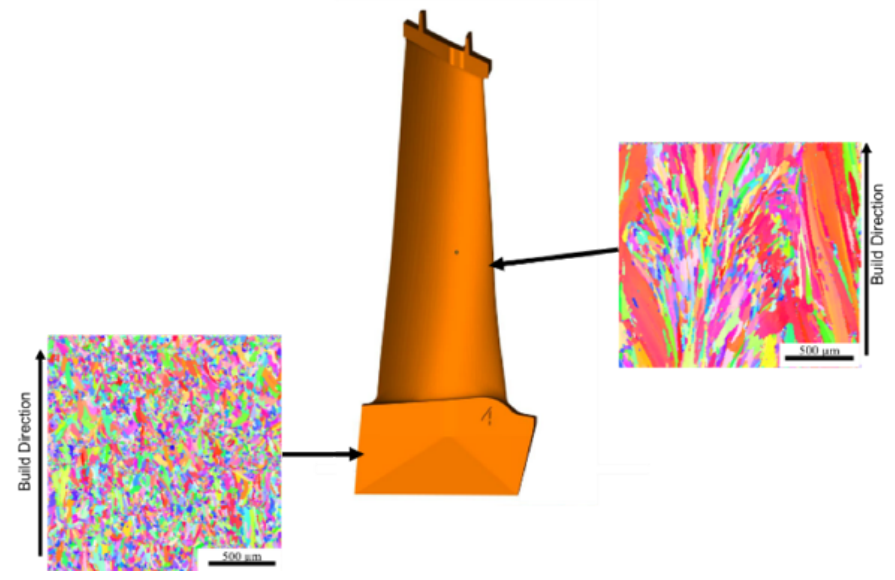

Figure 5: Textures formed within the modified airfoil geometry as a result of the optimized process parameters to yield crack free material.

\subsubsection{Mechanical Testing}

Rectangular bars measuring $15 \times 15 \times 100 \mathrm{~mm}$ were fabricated for mechanical testing of the AM material parallel to the build direction. For the transverse properties, blocks measuring $15 \times 100 \times 100 \mathrm{~mm}$ were produced. Prior to testing, the material was subjected to a HIP and heat-treatment to yield a microstructure discussed in the previous section.

At room temperature Tensile yield strength and elongation mechanical properties were superior to conventionally cast Inconel 738 AMS5410 specification requirements. Testing at intervals from room temperature to $1700^{\circ} \mathrm{F}$ revealed the EBM AM Inconel 738 yield strength was relatively constant from room temperature up to $1200^{\circ} \mathrm{F}$; however, between $1200^{\circ} \mathrm{F}$ and $1500^{\circ} \mathrm{F}$ a reduction in yield strength was noted (Figure 6). Elevated temperature Low Cycle Fatigue (LCF) testing at strain ranges from 0.6 to $1.0 \%$ strain produced LCF lives ranging from $\sim 8,000$ to 1.2 million cycles (Figure 7). Elevated temperature creep rupture testing resulted in stress rupture Larson Miller Parameters (LMP) values ranging from 41.5 to 46.1 when tested under applied stresses of 33 and $65 \mathrm{ksi}$. An exponential best fit trendline revealed the average AM material LMP creep rupture behavior is likely lower than the conventionally cast Inconel 738 AMS5410 specification requirements (Figure 8).
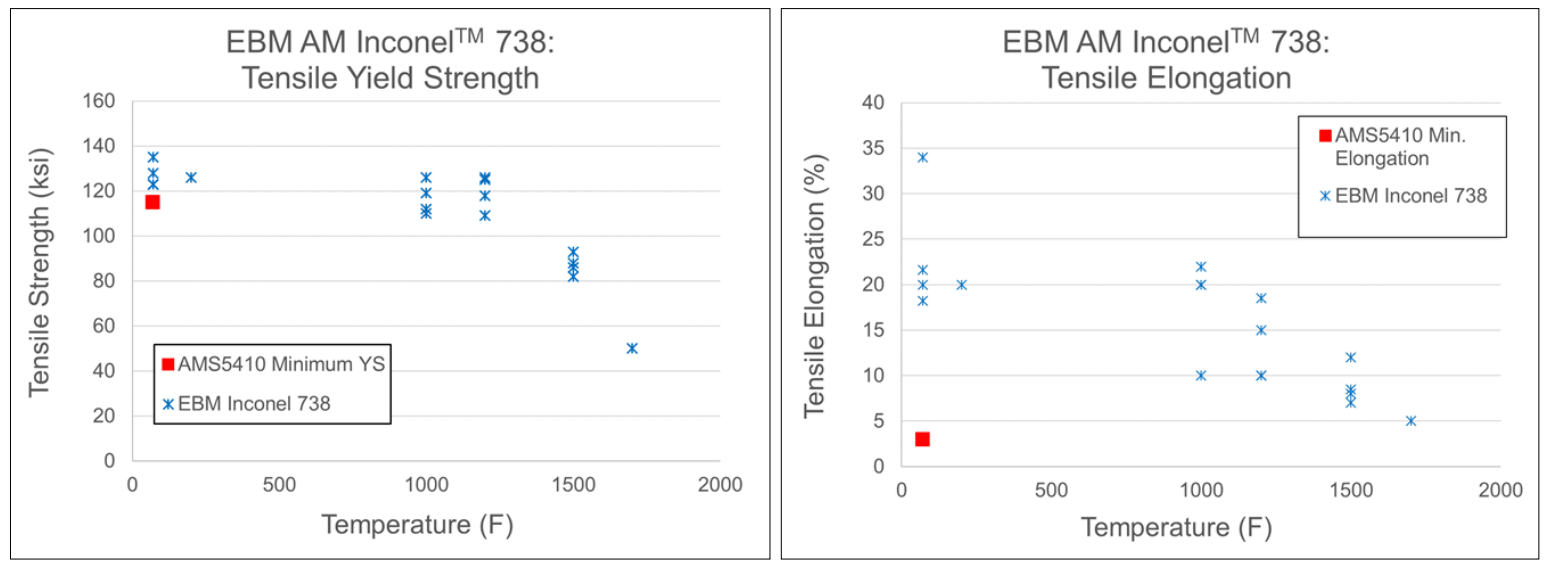

Figure 6: Tensile Properties of EBM AM Inconel ${ }^{\mathrm{TM}} 738$ samples that were machined from bars and walls after HIP, Solution, and Age heat treatment processing 


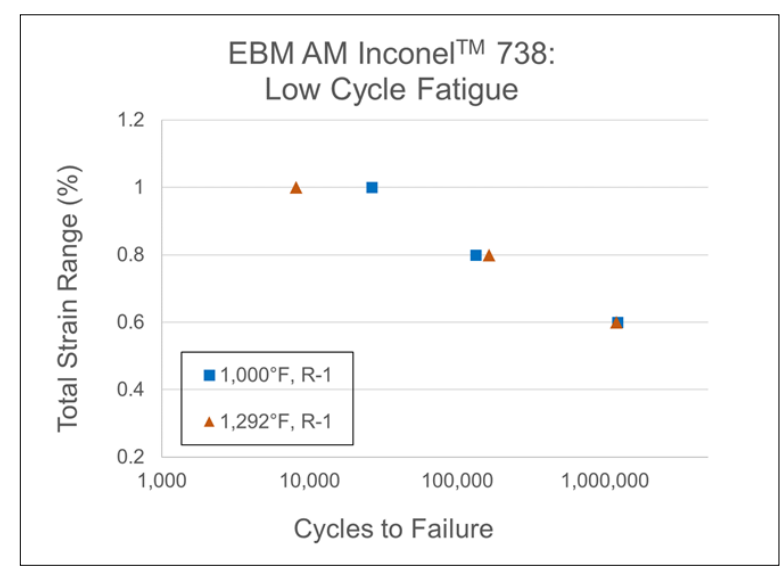

Figure 7: Low Cycle Fatigue (LCF) properties of EBM AM Inconel ${ }^{\mathrm{TM}} 738$ samples that were machined from bars and walls after HIP, Solution, and Age heat treatment processing

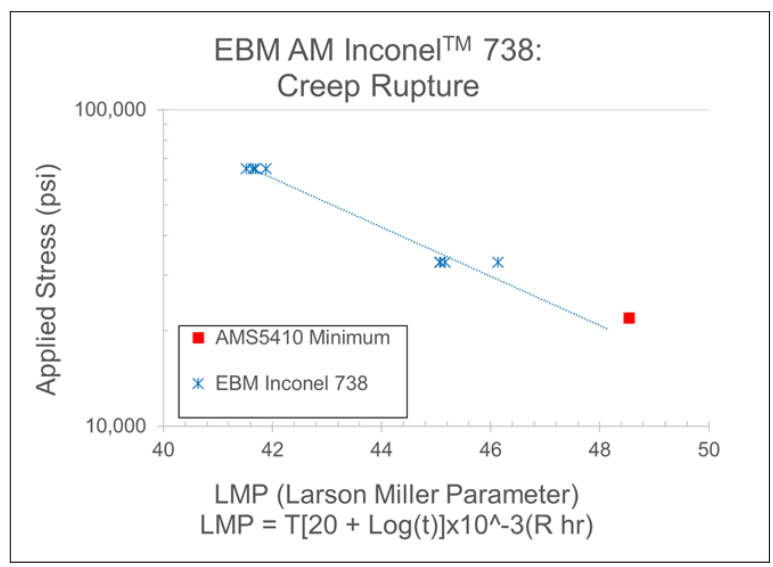

Figure 8: Creep Rupture Larson Miller Parameter (LMP) properties of EBM AM Inconel ${ }^{\mathrm{TM}} 738$ samples $^{-1}$ that were machined from vertical bars after HIP, Solution, and Age heat treatment processing

\subsubsection{Airfoil Feasibility Demonstration}

Utilizing the process parameters and beam scan path optimization discussed in the previous section, the design of the airfoil was modified from the actual geometry to that of something that could be printable. Initially, the unmodified geometry was printed, however, it was observed that cracks formed in preferential locations, mainly the overhang areas associated with the fir tree and within the leading edge of the airfoil. To overcome the cracking in the fir tree of the airfoil, the areas were filled-in to allow for a smoothed controlled transition in cross sectional areas of the base. Additionally, the cracking in the leading edge of the airfoil was eliminated through adjusting a combination of beam scan pattern rotation, and beam melt current. Shown in Figure 9 is an example of the successful airfoil geometry fabricated through EBM. 


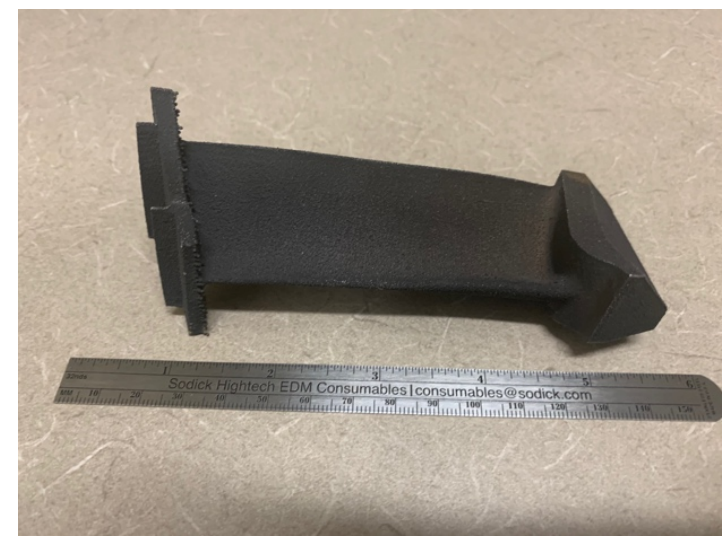

Figure 9: EBM Inconel 738 airfoil fabricated defect-free after geometry and process optimization.

\subsection{IMPACTS}

It is widely recognized that expertise in AM processes will yield significant competitive advantage and financial benefit to manufacturers. Product development cycle times can be reduced and product quality improved due to the rapid design and manufacturing iterative capability that AM technology provides.

In the industrial gas turbine (IGT) sector, Solar Turbines has previously gained expertise in additive manufacturing of Ni-based solid solution strengthened metallic materials suitable for low-stress, combustion system component; however, the application of this AM experience to historically investment cast and higher-value / higher-risk turbine hot-section components (blades, nozzles) has been limited. The barrier to successful AM processing of these high value components has been the severe cracking susceptibility of Ni-based gamma prime strengthened superalloys during AM processing.

In this Phase 1 project, the feasibility of AM processing Ni-based gamma prime strengthened materials (Inconel 738) has been demonstrated: (1) AM Inconel 738 microstructures and mechanical properties suitable for survival in a turbine engine hot-section were produced, and (2) A complex airfoil geometry capable of yielding a Mercury ${ }^{\mathrm{TM}} 50$ solid turbine blade was produced.

With this capability in hand, progress was been made toward the goal of rapid production of turbine blades capable of surviving an engine performance test. The engine performance test is a critical step in bringing a turbine engine to market and for implementation of product improvements. By removing the need for investment casting tooling from a project schedule critical path, the time and cost to achieve first engine to test can be reduced. The cost of investment cast tooling (typically ranging from $\$ 100 \mathrm{k}$ to $\$ 500 \mathrm{k}$ ) may be deferred. Additionally, this deferment of locking in the design of an investment cast tool can identify opportunities for additional design improvements that are revealed by the AM produced test articles.

This capability to AM process Ni-base superalloys will accelerate the validation of component design concepts, enabling turbine efficiency improvements needed to meet increasingly stringent customer and regulatory emissions requirements.

\subsubsection{SUBJECT INVENTIONS}

This section is not applicable to this program. 


\subsection{CONCLUSIONS}

Through scan strategy optimization the traditionally non-weldable Ni-base superalloy Inconel 738 can be successfully processed in a crack-free manner for both prismatic and complex geometries. The key to processing this material is developing the relationship between process parameters and geometry.

In developing this necessary processing science, the EBM Inconel 738 material was mechanically tested under tensile, fatigue, and creep conditions. The resultant mechanical tests showed that the material meet or exceeded the design curves for traditionally cast Inconel 738 demonstrating the feasibility of the EBM Inconel 738 material to be used for prototype blade applications such as the stage 2 of the Mercury 50 engine. As a result of this Phase 1 CRADA program the TRL level of EBM Inconel 738 was taken from a level of 2 and raised to a TRL level of 4.

To continue increasing the TRL level of this ORNL and Solar Turbines have pursued follow-on funding to enable a full scale hot-fire engine demonstration of prototype blades fabricated from Inconel 738 using the electron beam melting process. As a result of the success of this feasibility program, ORNL and Solar Turbines were able to secure the necessary funding to enable progression to developing the necessary processing science for blade fabrication and surface finishing of the complex geometry and if successful the TRL level of EBM Inconel 738 will be further increased to 7 . It is anticipated that the hot-fire engine test will occur in March of 2020 to demonstrate the capability of AM materials to server in functions for critical rotating components for harsh environments.

\section{PARTNER BACKGROUND}

Solar Turbines Incorporated, a wholly owned subsidiary of Caterpillar since 1981, headquartered in San Diego, California, employs approximately 8,000 employees, many of which are located at the headquarters in San Diego, California. Solar Turbines is a leading industrial gas turbine OEM, offering a range of gas turbines and turbomachinery equipment in the 1-23 MW range for oil \& gas exploration and transmission, and for power generation and cogeneration. Solar Turbines' state-of-the-art gas turbines are complemented by a line of compressors that can be matched with Solar Turbines equipment, or that of other OEMs. Over 15,000 gas turbines units and over 6,000 gas compressors, sold in over 100 countries, account for more than 2.7 billion fleet operating hours.

Solar Turbines has over 50 years of experience with the design, development and commercialization of industrial gas turbines and turbomachinery products. Solar Turbines has a long record of development of gas turbine technologies from internally funded and government programs. An example of a successful government-industry partnership was the DOE-Solar Advanced Turbine Systems (ATS) program, which resulted in the development of the 4.6 MWe Mercury 50 recuperated gas turbine. Solar Turbines has also been involved in the development of gas turbine products for renewable energy including bio-gas and solar energy. 